\title{
FLUID MICROINCLUSIONS IN MONOCRYSTALLINE DIAMONDS
}

\author{
Y. Weiss ${ }^{1}$, I. Kiflawi ${ }^{1}$, W.L. Griffin ${ }^{2}$ and O. Navon ${ }^{1}$ \\ ${ }^{1}$ The Institute of Earth Sciences, the Hebrew University of Jerusalem, Israel \\ ${ }^{2}$ GEMOC, Macquarie University, NSW, Australia
}

\section{INTRODUCTION}

The involvement of fluids in diamond formation is suggested by the morphology and symmetric growth patterns of the diamonds themselves (Sunagawa, 1981, 1984; Bulanova, 1995; Davies et al., 1999) and their common association with metasomatic minerals, veins and alteration zones in xenoliths (Meyer, 1987; Schulze et al., 1996; Keller et al., 1998; Taylor et al., 2000; Anand et al., 2004). Direct evidence is found in the form of microinclusions carrying high-density fluids (HDFs) with silicic, carbonatitic and saline compositions; these are common in fibrous diamonds and can also be found as clouds of inclusions within octahedral diamonds ("cloudy" diamond). It is widely accepted that these trapped HDFs represent the medium in which their host diamond grew.

Microinclusions carrying HDFs have not been documented in monocrystalline diamonds, allowing a debate on whether such fluids are responsible for the formation of all types of diamond. Indeed, it was suggested that mantle diamonds grow from reduced $\mathrm{C}-\mathrm{H}-\mathrm{O}$ fluids $\left(\mathrm{CH}_{4}\right.$-bearing fluids) as well (Cartigny et al., 1998; Cartigny, 2005; Thomassot et al., 2007; Stachel and Harris, 2009). This suggestion addresses mostly monocrystalline diamonds and is strongly based on variations in $\delta^{13} \mathrm{C}, \delta^{15} \mathrm{~N}$ and the $\mathrm{N}$ contents of such diamonds, which are consistent with predicted stableisotope fractionation due to diamond growth from methanerich fluid.

Other notable difference between fibrous and monocrystalline diamonds is that almost all nitrogen in the former resides in A-centers, whereas most monocrystalline diamonds carry both A- and B-centers. This is attributed to the antiquity of monocrystalline diamond compared with the short residence time of fibrous diamonds at mantle temperatures.

Here we report the first finding of HDF microinclusions in a monocrystalline octahedral diamond from Finsch, South Africa and in the octahedral core of a coated diamond from Kankan, Guinea. We carried out FTIR, EPMA and LAICP-MS analyses to characterize their compositions and compared it with those commonly found in fibrous diamonds.

\section{DIAMOND FINSCH 2A CAP1}

The microinclusions in the Finsch diamond are restricted to two thin layers, $\sim 10 \mu \mathrm{m}$ thick, parallel to the (111) face, $\sim 20$ and $200 \mu \mathrm{m}$ from the rim. Cathodoluminescence (CL) reveals concentric zoning, characteristic of monocrystalline growth throughout the diamond and all the way to the rim. The inclusion-rich layers are easily recognized by their weak fluorescence (Figure 1).

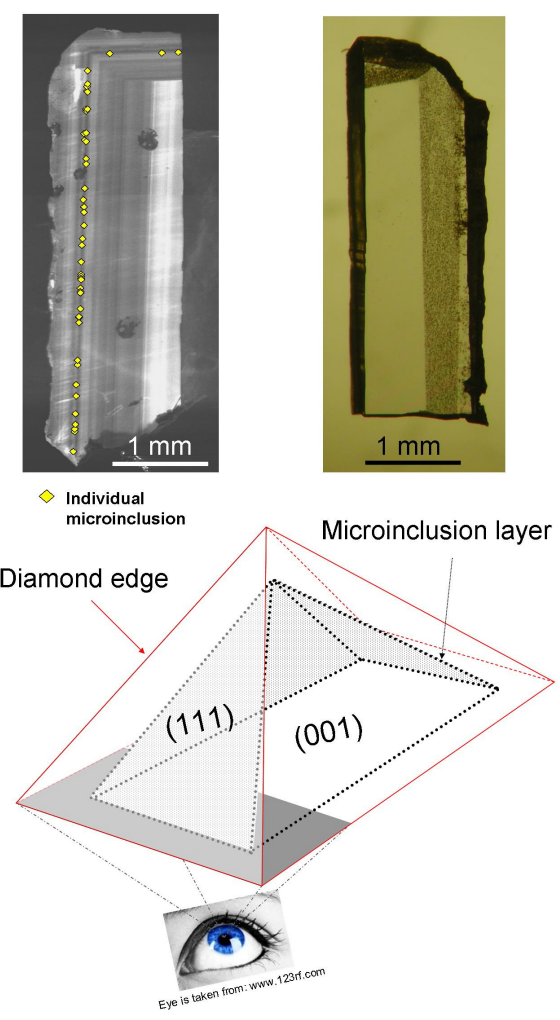

Figure 1: Transmitted light and Cathodoluminescence (CL) images of diamond Finsch 2a cap1. Both images were taken perpendicular to the (001) plane. The half octahedron below illustrates the photographed plane (gray rectangle) and the position and orientation of the microinclusion layer relative to this plane. The observer's eye is from www.123rf.com. 


\section{$10^{\text {th }}$ International Kimberlite Conference, Bangalore - 2012}

The diamond carries $\sim 800-1200$ ppm nitrogen. Absorbance by $\mathrm{B}$ centres is observed in the inner part $(\mathrm{A} / \mathrm{B}=5)$ as well as between the inclusion-rich layers and the diamond rim $(\mathrm{A} / \mathrm{B}=16)$. Using the calibration of Taylor et al. (1996), we estimate that the rim of this diamond formed $100 \mathrm{Myr}$ before eruption at $1150^{\circ} \mathrm{C}$ or earlier at lower temperatures. IR spectra taken at the microinclusion-rich part reveal weak absorbance at 877 and $1440 \mathrm{~cm}^{-1}$, similar to the carbonate bands in fibrous diamonds carrying HDFs.

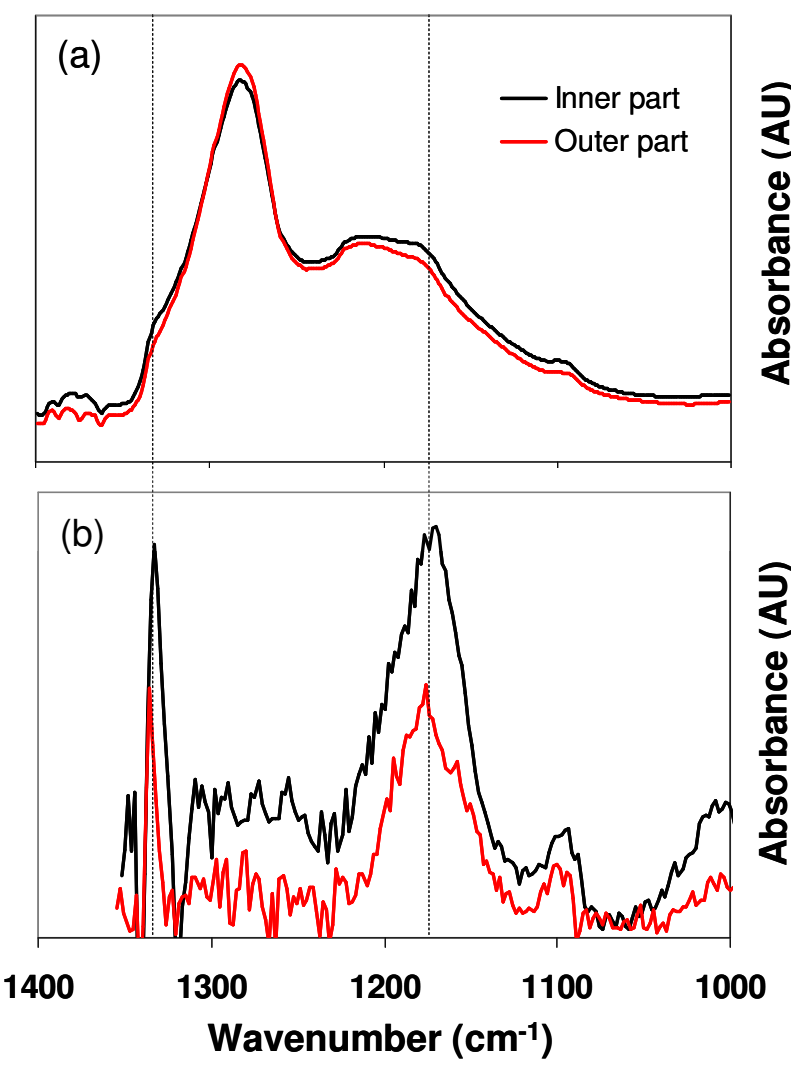

Figure 2: IR spectrum due to nitrogen absorbance in diamond Finsch_2a_cap1. (a) raw data and (b) residual absorbance after subtraction of a pure IaA spectrum, showing the characteristic peaks at 1170 and 1332 $\mathrm{cm}^{-1}$ due to B-center aggregation. The black line is the spectrum taken at the inner part of the diamond and red line stands for absorbance in the outer part (between the inner microinclusions layer and the diamond rim).

Forty-five microinclusions of carbonatitic HDF compositions were analyzed along the inner layer (Figure 1). Their average major element composition has $\mathrm{CaO}=29.6 \mathrm{wt} \%, \quad \mathrm{MgO}=11.5, \quad \mathrm{FeO}=10.1, \quad \mathrm{SiO}_{2}=7.8$, $\mathrm{Al}_{2} \mathrm{O}_{3}=2.2, \mathrm{~K}_{2} \mathrm{O}=11.8, \mathrm{Na}_{2} \mathrm{O}=16.6$ and $\mathrm{Cl}=4.0 \mathrm{wt} \%$, close to that of the low-Mg carbonatitic HDF end-member found in many fibrous diamonds (Figure 3). The compositional variation of $\mathrm{SiO}_{2}+\mathrm{Al}_{2} \mathrm{O}_{3}$ vs. $\mathrm{CaO}+\mathrm{MgO}+\mathrm{FeO}$ in individual fluid inclusions correlates negatively, a characteristic of all carbonatitic to silicic HDFs in fibrous diamonds.

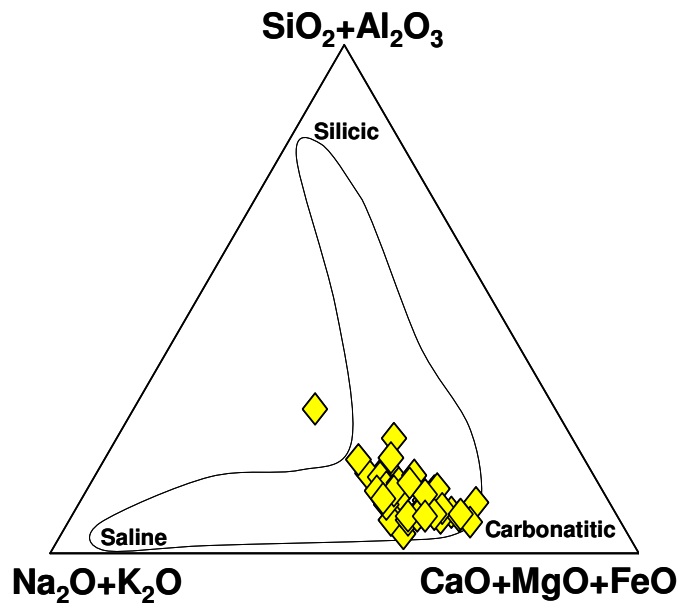

Figure 3: Ternary diagram of silicic, carbonatitic and saline compositions showing the range of compositions spanned by the HDF microinclusions in fibrous diamonds, as determined by average compositions of individual diamonds (black line). The compositions of microinclusions that were analyzed in the monocrystalline diamond Finsch_2a_cap1 (yellow diamond) are not exceptional; they fall within the range of carbonatitic HDFs.

Primitive-mantle-normalized trace-element compositions of the trapped HDFs at the inner and outer layer show distinct patterns (Figure 4). The outer-layer inclusions are characterized by smooth patterns with moderate decrease towards the more compatible elements, while the inner layer has elevated $\mathrm{Ba}, \mathrm{U}$, Th and REE and depleted alkalis. The two patterns resemble the "Bench" and "Table" patterns observed in fibrous diamonds (10IKC abstract No. 174), except for the high $\mathrm{Ta}$ and $\mathrm{Nb}$ in the latter.

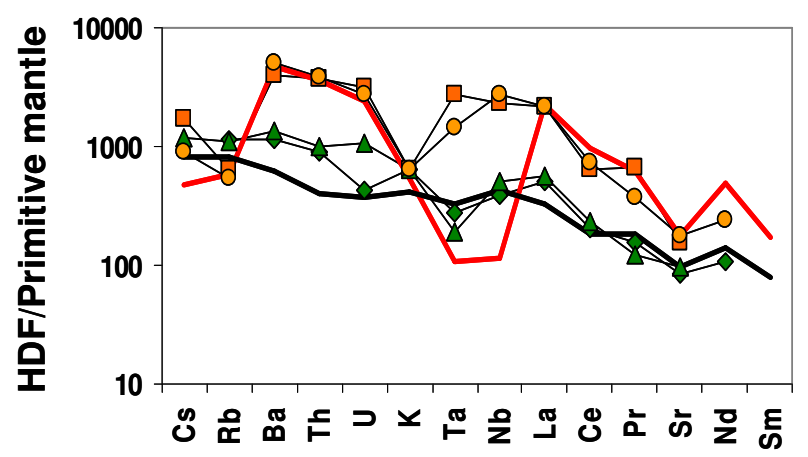

Figure 4: Primitive-mantle normalized trace-element patterns of the microinclusions along the inner layer (orange circles and squares) and outer layer (green diamonds and triangles) in diamond Finsch_2a_cap1. The solid red and black lines show representative "Table" and "Bench" patterns, respectively, in fibrous diamonds. 


\section{$10^{\text {th }}$ International Kimberlite Conference, Bangalore - 2012}

Changes in the trace-element pattern within a single fibrous diamond are usually associated with changes in the majorelement composition of the trapped HDF. The LA-ICP-MS analyses do not show significant changes in the pattern of $\mathrm{Ca}, \mathrm{Mg}, \mathrm{Fe}, \mathrm{Al}$, and $\mathrm{Na}$ between the inner- and outer-layer inclusions in diamond Finsch_2a_cap1. We intend to analyze the outer-layer inclusions using EPMA, which will also provide the composition of $\mathrm{Si}$ and $\mathrm{Cl}$, for better characterization.

\section{DIAMOND ON-KAN-383}

In the octahedral core of the Kankan diamond we found six microinclusions with saline compositions, corresponding to the Na-rich compositions of saline HDFs (Figure 5). Unlike the case of the Finsch diamond, these inclusions are sporadically scattered, up to $\sim 100 \mu \mathrm{m}$ away from a sulfide mineral inclusion in the core of the diamond.

The core carries nitrogen in $\mathrm{A}$ and $\mathrm{B}$ centres, with $\mathrm{A} / \mathrm{B}=18$.

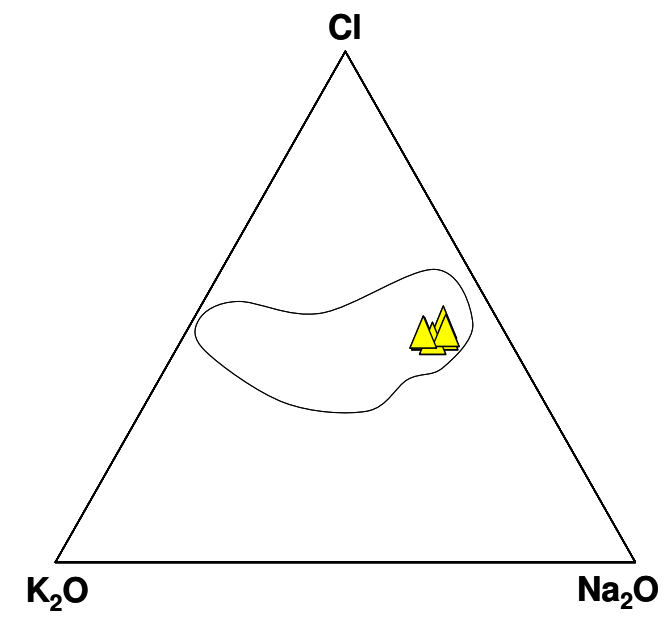

Figure 5: Ternary diagram for saline compositions showing the range of compositions spanned by the HDF microinclusions in fibrous diamonds from DeBeers Pool (black line; Weiss unpublished data), as determined by average compositions of individual diamonds. The microinclusions that were analyzed in the core of ON-KAN-383 (yellow diamonds) have Narich saline composition.

\section{DIAMOND FORMING-FLUIDS - OXIDIZED vs. REDUCED FLUIDS}

The various HDFs found as inclusions in fibrous diamonds, all carry carbonates. Together with their host diamond they define an oxidized environment, close to the EMOD buffer. Stachel et al. (2004) modeled the formation of sinusoidal REE patterns in garnets, found as inclusions in monocrystalline diamonds, as interaction of depleted lithospheric garnets with $\mathrm{C}-\mathrm{O}-\mathrm{H}$ fluids carrying very high concentrations of LREE and incompatible elements. The HDFs are excellent candidates for such fluids, suggesting the enrolment of oxidized fluids in the formation of many diamonds (Weiss et al., 2009). Supportive evidence for such interaction comes from the similarity of trace element patterns of minerals trapped as inclusions in fibrous and monocrystalline diamonds (Tomlinson et al., 2009).

Alternatively, Malkovets et al. (2007) suggested that the formation of such garnets and their host diamond is related to the oxidation of asthenosphere-derived, methane-rich fluids. Similar suggestions, advocating diamond growth from methane-rich fluids were made previously (Cartigny et al., 1998; Cartigny, 2005; Thomassot et al., 2007; Stachel and Harris, 2009), based mostly on carbon isotopic data. Experiments by Tomilenko et al. (1998) indicated that, indeed, diamonds can crystallize from $\mathrm{CH}_{4}$ in the mantle environment. However, except for a single report of direct detection of reduced gases in inclusions within a single Siberian diamond (Raman spectroscopy, Tomilenko et al., 1997), inclusions of $\mathrm{CH}_{4}$-bearing fluids have not been found in natural diamonds.

The observations above and the composition of the HDFs we found in monocrystalline diamonds, suggest that oxidized fluids may serve as the growth medium for monocrystalline diamonds as well. We have good reasons to believe that microinclusions and HDFs will be found in other monocrystalline diamonds, extending the role of HDFs to the formation of such diamonds.

\section{References}

Anand, M., Taylor, L.A., Misra, K.C., Carlson, W.D., Sobolev, N.V., 2004. Nature of diamonds in Yakutian eclogites: views from eclogite tomography and mineral inclusions in diamonds. Lithos 77, 333-348.

Bulanova, G.P., 1995. The formation of diamond. Journal of Geochemical Exploration 53 (1-3), 1-23.

Cartigny, P., 2005. Stable isotopes and the origin of diamond. Elements 1, 79-84.

Cartigny, P., Harris, J.W., Javoy, M., 1998. Eclogitic diamond formation at Jwaneng: no room for a recycled component. Science 280, 1421-1423.

Davies, R.M, O'Reilly, S.Y. and, Griffin, W.L., 1999. Growth structures and nitrogen characteristics of Group B alluvial diamonds from Bingara and Wellington, Eastern Australia. In Proceedings of the Proc. $7^{\text {th }}$ International Kimberlite Conference, vol. 1, 156-163.

Keller, R.A., Taylor, L.A., Snyder, G.A., Sobolev, V.S., Carlson, W.D., Sobolev, N.V., Pokhilenko, N.P., 1998. 3-D petrography of diamondiferous eclogite from Udachnaya, Siberia. Extended Abstracts, $7^{\text {th }}$ International Kimberlite Conference, Capetown 1998, 405-407.

Malkovets, V.G., Griffin, W.L., O'Reilly, S.Y., Wood, B.J., 2007. Diamond, subcalcic garnet, and mantle metasomatism: kimberlite sampling patterns define the link. Geology 35, 339-342.

Meyer, H.O.A., 1987. Inclusions in diamond. In: Nixon, P.H. (Ed.), Mantle Xenoliths, John Wiley \& Sons, Chichester, U.K, 501-522.

Schulze, D.J., Wiese, D., Steude, J., 1996. Abundance and distribution of diamonds in eclogite revealed by volume visualization of CT X-ray scans. Journal of Geology 104, 109-114.

Stachel, T. and Harris, J.W., 2009. Formation of diamond in the Earth's mantle Journal of Physics: Condensed Matter 21, 1-10.

Stachel, T., Aulbach, S., Brey, G.P., Harris, J.W., Leost, I., Tappert, R., Viljoen, K.S., 2004. The trace element composition of silicate inclusions in diamonds: a review. Lithos 77, 1-19. 


\section{$10^{\text {th }}$ International Kimberlite Conference, Bangalore - 2012}

Sunagawa, I., 1981. Characteristics of Crystal Growth in Nature as Seen From the Morphology of Mineral Crystals. Bulletin de Mineralogie 104: 81-87

Sunagawa, I., 1984. Morphology of natural and synthetic diamond crystals. Materials science of the Earth's interior, Terra. Scientific Publishing, TokyoTerra Sci. Publ., Tokyo, Japan, 303-330.

Taylor, L.A., Keller, R.A., Snyder, G.A., Wang, W.Y., Carlson, W.D., Hauri, E.H., McCandless, T., Kim, K.R., Sobolev, N.V. and, Bezborodov, S.M., 2000. Diamonds and their mineral inclusions, and what they tell us: A detailed "pull-apart" of a diamondiferous eclogite. International Geology Review 11, 959-983.

Taylor, W.R., Canil, D., Milledge, J., 1996. Kinetics of Ib to IaA nitrogen aggregation in diamond. Geochimica et Cosmochimica Acta 60, 47254733.

Thomassot, E., Cartigny, P., Harris, J.W. and Viljoen, K.S., 2007. Methane-related diamond crystallization in the Earth's mantle: Stable isotope evidences from a single diamond-bearing xenolith Earth and Planetary Science Letters 257, 362-371.

Tomilenko, A.A., Chepurov, A.I., Palyanov, Y.N., Pokhilenko, L.N., Shebanin, A.P., 1997, Volatile components in the upper mantle (from data on fluid inclusions), Geologiya I Geofizika 38, 276-285.

Tomilenko, A.A., Chepurov, A.I., Pal'yanov, Y.N., Shebanin, A.P. and Sobolev, N.V., 1998. Hydrocarbon inclusions in synthetic diamonds. European Journal of Mineralogy 10. 1135-1141.

Tomlinson, E.L., Müller, W. EIMF, 2009. A snapshot of mantle metasomatism: Trace element analysis of coexisting fluid (LA-ICP-MS) and silicate (SIMS) inclusions in fibrous diamonds. Earth and Planetary Science Letters, Volume 279, 362-372.

Weiss, Y., Kessel, R., Griffin, W.L., Kiflawi, I., Klein-BenDavid, O., Bell, D.R., Harris, J.W., Navon, O., 2009. A new model for the evolution of diamond-forming fluids: evidence from microinclusion-bearing diamonds from Kankan, Guinea. Lithos 112, 660-674. 